María Pilar Celma Valero

Carmen Morán Rodríguez (coords.)

La verdadera patria

Infancia y adolescencia en el relato español contemporáneo 


\section{Ediciones de Iberoamericana}

Consejo editorial:

Mechthild Albert

Rheinische Friedrich-Wilhelms-Universität, Bonn

Daniel Escandell Montiel

Universidad de Salamanca

Enrique García-Santo Tomás

University of Michigan, Ann Arbor

Aníbal González

Yale University, New Haven

Klaus Meyer-Minnemann

Universität Hamburg

Daniel Nemrava

Palacky University, Olomouc

Emilio Peral Vega

Universidad Complutense de Madrid

Janett Reinstädler

Universität des Saarlandes, Saarbrücken

Roland Spiller

Johann Wolfgang Goethe-Universität, Frankfurt am Main 


\title{
La verdadera patria Infancia y adolescencia en el relato español contemporáneo
}

\author{
María Pilar Celma Valero \\ Carmen Morán Rodríguez (coords.)
}


Este libro se ha realizado en el marco del Proyecto de Investigación I+D "La narrativa breve espańola actual: estudio y aplicaciones didácticas" (DGCYT FFI2015-70094-P), financiado por el Ministerio de Economía y Competitividad dentro del Programa Estatal de Fomento de la Investigación científica y técnica de excelencia (Subprograma estatal de Generación de conocimiento). Forma, además, parte de las actividades desarrolladas por el GIR-LEC (Grupo de Investigación Reconocido "Literatura Española Contemporánea” de la Universidad de Valladolid).

Cualquier forma de reproducción, distribución, comunicación pública o transformación de esta obra solo puede ser realizada con la autorización de sus titulares, salvo excepción prevista por la ley. Diríjase a CEDRO (Centro Espańol de Derechos Reprográficos) si necesita fotocopiar o escanear algún fragmento de esta obra (www.conlicencia.com;

917021970 / 932720447$)$.

\section{Derechos reservados}

(C) Iberoamericana, 2019

Amor de Dios, 1 - E-28014 Madrid

Tel.: +34914293522 - Fax: +34914295397

(C) Vervuert, 2019

Elisabethenstr. 3-9 - D-60594 Frankfurt am Main

Tel.: +49695974617 - Fax: +49695978743

info@iberoamericanalibros.com

www.iberoamericana-vervuert.es

ISBN 978-84-9192-075-5 (Iberoamericana)

ISBN 978-3-96456-887-8 (Vervuert)

ISBN 978-3-96456-888-5 (e-Book)

Depósito Legal: M-26228-2019

Diseño de la cubierta: a.f. diseño y comunicación

Imagen de cubierta: Story of Golden Looks (ca. 1870), Seymour Joseph Guy. Metropolitan Museum of Art, Nueva York

Impreso en España

Este libro está impreso íntegramente en papel ecológico sin cloro. 